\title{
Jelena Mihaljević Diigunović ATTITUDES OF YOUNG FOREIGN LANGUAGE LEARNERS: A FOLLOW-UP STUDY
}

The popular belief that young children are the best foreign language learners has been put to test in numerous studies but the findings have been far from conclusive. The researchers who take the view that there is at least some potential advantage to an early start still do not agree on the precise nature of such an advantage. The causes of such an advantage are a matter of dispute as well.

Carroll (1969:63) claims that "the amount of competence one achieves is largely a matter of time spent in learning, rather than the actual age of starting". In his rejection of the sensitive period in favour of the concept of cognitive maturation, Vogel (1991) concludes that older learners are superior to younger ones. Dabene (1991) states that, while it is generally accepted that younger children are better at learning languages, the learner's age is only one of many factors involved.

It is interesting to note that in spite of the findings of even such studies as the Nuffield French in the Primary School (Burstall, Jamieson, Cohen \& Hargreaves, 1974) that early starters had definitely more favourable attitudes to the foreign language and culture, the cultural and educational value of meeting a new language during an early age and the high motivation that was shown by most pupils and teachers are often ignored. Lennon (1993) stresses that the young learner is far more open to new cultural and linguistic influences because his cognitive, attitudinal, social and psychological development is not completed. Considering an early start a good chance to promote positive attitudes to language learning because the young learner is still at a highly impressionable age, Johnstone also stresses the opportunity for "experiential forms of learning based on the kinds of project-work, creative activity, song, dance, drama and practical tasks (....) What has been assimilated intuitively and experientially may then be reprocessed in more analytical, cognitive ways when children are somewhat older." (1993:2) Several authors point out that it is in circumstances where the individual feels unthreatened and unchallanged that the affective filter is most likely to be lowered and ego permeability increased.

If one accepts the concept of the "critical" or "sensitive" period for learning a language, in this case a foreign language, one may also consider the possibility of there being multiple sensitive periods for various aspects of language learning, thus a sensitive period for the development of the affective aspects of this process. 


\section{Aim}

After learning about the attitudes of 7-year-old beginners in English, French and German within the Zagreb Project 1991 (see Mihaljević Djigunović, 1993) in the followup study we were interested in seeing the development of these initial attitudes after almost three years of learning the foreign language in question. Our interest particularly focused on whether the young beginners viewed their foreign language classes differently now, whether their attitudes towards the native speakers of the language they were learning changed and whether their self-rating of foreign language skills changed.

\section{Instruments}

The same interview that was used in the initial year of the Project (1991/1992 school year; see earlier chapter on attitudes and motivation in this volume) was applied at the end of the third year of learning.

The 22 questions included in the interview probed the following attitude objects: the foreign language, native speakers of the foreign language, the purpose of learning the foreign language, the optimal age to start foreign language learning, foreign language lessons in school and the learner's attainment in the foreign language. The learners were also questioned on whether they had known a bit of the foreign language before starting school as well as which members in the family spoke foreign languages.

\section{Sample}

At the end of the third year of learning 281 young learners were examined. The sample included 146 male and 135 female learners.

There were 87 learners of English, 86 learners of French and 108 learners of German as a foreign language. Since this first generation of young learners had no firstgrade (7 years of age) beginners of Italian, learners of Italian were not included in this particular study of attitudes and motivation.

The young learners in this study were now all third-graders and in their third year of learning the foreign language in question. Four classes of learners from four different schools in Zagreb were included for each of the three foreign languages.

\section{Methodology}

Each young learner was interviewed by the interviewer individually out of class in a separate room. The interviewer followed the instructions that apply to oral interviews with such young interviewees. Answers given by the children were noted down 
on the spot and additional comments were written after the child had left the room. Most interviewees were very cooperative and, on the whole, the interviews went very smoothly.

\section{Results and discussion}

The statistical results to be presented in this section will be grouped according to the object of the attitude investigated. Comparisons will be made with the results of the first interview (Mihaljević Djigunović, 1993).

\section{Item 1: What is your favourite school subject?}

The learners were asked about their favourite school subject. The aim was to find out how many would name the foreign language as the favourite subject in school.

The following percentages of the young learners stated that the foreign language was their favourite subject:

\begin{tabular}{|l|l|}
\hline English & $29.9 \%$ \\
\hline French & $29.1 \%$ \\
\hline German & $15.7 \%$ \\
\hline
\end{tabular}

Compared to the results of the interview two years earlier it seems that English was mentioned as the most favourite subject significantly more frequently $(12.0 \%$ 29.9\%). The other two languages did not differ much in the frequency of appearing as the favourite school subject.

The importance of these answers is downplayed by the fact that, as noticed in earlier studies (e.g., Vilke, 1976), a large number of learners do not think of the foreign language as a school subject but as a nicely spent time in school. This is supported by the answers to Items 2 \& 3.

Item 2: Do you like the foreign language you are learning?

Item 3: Do you enjoy your foreign language classes?

The results were almost identical to those from the first interview. Item 2:

\begin{tabular}{|l|l|l|l|}
\hline & English & French & German \\
\hline YES & $98.9 \%$ & $97.7 \%$ & $97.2 \%$ \\
\hline
\end{tabular}


Item 3:

\begin{tabular}{|l|l|l|l|}
\hline & English & French & German \\
\hline YES & $98.9 \%$ & $98.8 \%$ & $96.2 \%$ \\
\hline
\end{tabular}

At the end of the third year of learning our early starters still liked both the foreign language they were learning and the foreign language classes.

\section{Item 4: What do you do in your foreign language classes?}

The purpose of this item was to find out what perceptions the young learners had of what went on in their foreign language classes.

The answers were classified according to whether they referred to activities that imply teaching/learning elements (e.g., learning words) or game elements (e.g., singing). Thus three groups were formed:

\begin{tabular}{|l|l|l|l|}
\hline & English & French & German \\
\hline Teaching & $29.3 \%$ & $29.1 \%$ & $33.0 \%$ \\
\hline Playing & $11.0 \%$ & $24.4 \%$ & $6.6 \%$ \\
\hline Both & $59.8 \%$ & $46.5 \%$ & $60.4 \%$ \\
\hline
\end{tabular}

In all the three foreign language groups the percentage of learners who described activities in class as learning increased significantly. Except for the learners of French, the percentage of learners who saw their foreign language classes as playing dropped.

It is essential that young foreign language learners view their learning as pleasant. Unless their experience is positive it may result in antipathy towards the language and culture they are learning and demotivation for subsequent learning.

Several authors (e.g., Schumann, 1978) stress the role of the psychological distance, which is defined as the learner's degree of ease or unease with the foreign language and culture as well as of the learner's personal motivation and permeability of ego. Curran (1961) claims that children on the whole may feel less threatened by the new sounds and are willing to depend on others for support in learning as opposed to adults and this makes them acquire more easily. Stengel (1939) believes that giving a child a new language is giving him a new method of play; the child has no fear of talking nonsense (it may even be a source of pleasure for the child) or pretence.

We can see that at age 9 fewer children saw foreign language learning as play than at age 7 .

Item 5: What do like most in your foreign language classes? 
Item 6: What do you dislike most in your foreign language classes?

The same classification criterion was used to analyze the results of these two items. Item 5

\begin{tabular}{|l|c|c|c|}
\hline & English & French & German \\
\hline Teaching & $25.3 \%$ & $48.8 \%$ & $31.8 \%$ \\
\hline Playing & $70.1 \%$ & $47.7 \%$ & $59.8 \%$ \\
\hline Both & $4.5 \%$ & $3.5 \%$ & $8.4 \%$ \\
\hline
\end{tabular}

Except for the learners of German, where the results do not significantly differ from those of two years earlier, in most other cases more learners stated learning/teaching activities as their favourite. On the one hand, it is possible that they were now capable of perceiving learning elements more easily (this is, in fact, supported by the results in Item 4!) but, on the other, it is also likely that the learners started getting more pleasure out of learning and a sense of achievement.

Item 6

\begin{tabular}{|l|l|l|l|}
\hline & English & French & German \\
\hline Teaching & $29.3 \%$ & $29.1 \%$ & $48.5 \%$ \\
\hline Playing & $11.0 \%$ & $24.4 \%$ & $26.2 \%$ \\
\hline Nothing & $59.8 \%$ & $46.5 \%$ & $25.2 \%$ \\
\hline
\end{tabular}

Teaching/learning activities had dropped in the frequency of being disliked by the young learners, the change being less drastic with the learners of German. The same decline can be observed with playing activities (a drastic one in the case of learners of French!). The changes in the percentages may be ascribed to the new group of answers that appeared here: "I like everything that goes on in the classroom."

It is encouraging that the initial positive attitudes of the young beginners in the Project spread to most of the classroom events in the two years that passed since the first interview.

Item 7: Would you like to continue learning the foreign language next year too?

Item 12: Would you be sorry if your parents hadn't enrolled you in this programme?

An important aspect of motivation is the wish to continue the activity one is engaged in and these two items aimed at finding out about this in our beginners. 
Item 7:

\begin{tabular}{|l|l|l|l|}
\hline & English & French & German \\
\hline YES & $100 \%$ & $95.3 \%$ & $98.1 \%$ \\
\hline
\end{tabular}

An overwhelming number of the young beginners still wanted to go on learning the foreign language after three years of learning. The wish they had expressed two years earlier did not vanish. This may be ascribed to the fact that the learners enjoyed their foreign language lessons and had a feeling they had achieved a lot of knowledge and skill.

Item 12

\begin{tabular}{|l|l|l|l|}
\hline & English & French & German \\
\hline YES & $95.4 \%$ & $91.8 \%$ & $94.4 \%$ \\
\hline
\end{tabular}

Again, the vast majority were happy that their parents had enrolled them in the experimental class. Although the differences are not statistically significant, one may note again the slightly higher percentage of the learners of French who would not be too unhappy about not being in the Project.

Item 8: Which mark would you assign yourself for the foreign language you are learning?

The learners were asked to evaluate their knowledge of the foreign language on a 1-5 scale (1-insufficient, 5-excellent).

Item 8

\begin{tabular}{|l|c|l|l|}
\hline & English & French & German \\
\hline excellent & $58.6 \%$ & $39.5 \%$ & $29.9 \%$ \\
\hline very good & $35.6 \%$ & $54.7 \%$ & $51.4 \%$ \\
\hline good & $3.4 \%$ & $5.8 \%$ & $15.9 \%$ \\
\hline fair & $0 \%$ & $0 \%$ & $1.9 \%$ \\
\hline insufficient & $0 \%$ & $0 \%$ & $.9 \%$ \\
\hline
\end{tabular}

The average mark that the learners assigned themselves differs significantly from the grade they stated two years earlier. It dropped from 4.6 to 4.3 for all the three groups of learners. In the case of learners of English the drop was not significant, while the greatest drop in the average grade was found with the learners of German (from 4.6 to 4.0$)$. 
Although the young learners still thought highly of their learning achievements, they seemed to be more objective and realistic when evaluating their proficiency in terms of marks. There may be two explanations for this: they were not only more mature now but had also had feedback from the foreign language teacher on their learning achievements. They were also more aware of teaching going on in class and may have started evaluating themselves according to concrete learning results.

Item 9: Is it good to know the foreign language you are learning?

Item 10: Why is it good to know the foreign language you are learning?

Item 11: Why is it good for you to know this foreign language?

The purpose of the three items was to find out what benefits the learners saw in knowing the foreign language they were learning and whether these changed over the two-year period.

Item 9

\begin{tabular}{|l|l|l|l|}
\hline & English & French & German \\
\hline YES & $98.1 \%$ & $100 \%$ & $100 \%$ \\
\hline
\end{tabular}

Again, the overwhelming majority believe it was good to know the foreign language they were learning.

Item 10

\begin{tabular}{|l|l|l|l|}
\hline & English & French & German \\
\hline $\begin{array}{l}\text { Communication/ } \\
\text { Travel }\end{array}$ & $61.6 \%$ & $76.5 \%$ & $72.0 \%$ \\
\hline Language features & $16.3 \%$ & $9.4 \%$ & $6.5 \%$ \\
\hline $\begin{array}{l}\text { General } \\
\text { knowledge }\end{array}$ & $14.0 \%$ & $10.6 \%$ & $11.2 \%$ \\
\hline $\begin{array}{l}\text { Education/job } \\
\text { opportunities }\end{array}$ & $5.8 \%$ & $2.4 \%$ & $7.5 \%$ \\
\hline Don't know & $2.3 \%$ & $1.2 \%$ & $2.8 \%$ \\
\hline
\end{tabular}

The answers lent themselves to five groups. Some answers referred to practical benefits of the knowledge, some were connected with the linguistic or cultural and educational value.

The same classification of answers was possible with answers to Item 11. 
Item 11

\begin{tabular}{|l|c|c|c|}
\hline & English & French & German \\
\hline $\begin{array}{l}\text { Communication/ } \\
\text { Travel }\end{array}$ & $86.2 \%$ & $77.9 \%$ & $78.5 \%$ \\
\hline Language features & $1.1 \%$ & $0 \%$ & $.9 \%$ \\
\hline $\begin{array}{l}\text { General } \\
\text { knowledege }\end{array}$ & $3.4 \%$ & $4.7 \%$ & $4.7 \%$ \\
\hline $\begin{array}{l}\text { Education/job } \\
\text { opportunities }\end{array}$ & $3.4 \%$ & $16.3 \%$ & $13.1 \%$ \\
\hline Don't know & $5.7 \%$ & $1.2 \%$ & $2.8 \%$ \\
\hline
\end{tabular}

The second interview showed that in the third grade young learners could distinguish between general and personal benefits. It is interesting to note that in the first interview a certain number of young beginners did not know whether it was good to know a foreign language but could still provide an answer about the benefits of the knowledge of the foreign language they were learning. In the second interview the situation is the opposite: no learner said he did not know whether knowing the foreign language was good but when it came to explaining why the "don't know" answers appeared.

The analysis of the answers shows that as far as the communication/travel benefit is concerned, the learners of English mentioned it less frequently now than two years earlier in contrast with the learners of German. Language features (e.g., ease of learning, usefulness) were more often stressed now with the learners of English and less often with the learners of German than in the first interview. Increasing one's general knowledge went up in all the groups but especially with the learners of English. Educational and job opportunities as a general benefit appeared now less often in the English and German groups but its frequency went up with the learners of French.

As far as personal benefits of knowing the foreign language in question are concerned the communication/travel benefits increased in the English group, decreased in the French group and remained at the same frequency level in the German group. Language features remained at the same level in the English group as well as in the French group (where the frequency was again 0!) and increased a bit in the German group. General knowledge as a personal benefit increased in the German group. It is interesting to note that better opportunities for schooling and work in future appeared more frequently now only in the French and German groups and not in the English group. It seems that our young learners of the three foreign languages were instrumentally oriented and that they tended to see vocational rather than cultural value (Singleton, 1989) in knowing the foreign language they were learning. 
Item 13: What do you think is the best time to start learning a foreign language?

We were interested in what, according to the young learners, the optimal age for starting foreign language learning was.

Item 13

\begin{tabular}{|l|c|c|c|}
\hline & English & French & German \\
\hline Pre-school & $46.0 \%$ & $38.4 \%$ & $38.3 \%$ \\
\hline 7 years & $50.6 \%$ & $48.8 \%$ & $58.9 \%$ \\
\hline 8 years & $2.3 \%$ & $5.8 \%$ & $.9 \%$ \\
\hline 9 years & $0 \%$ & $1.2 \%$ & $0 \%$ \\
\hline 10 years & $0 \%$ & $2.3 \%$ & $1.9 \%$ \\
\hline later & $1.1 \%$ & $3.5 \%$ & $0 \%$ \\
\hline
\end{tabular}

As in the first interview, the majority of learners in all the groups believed that the first grade of primary school was the optimal time to start learning a foreign language. In contrast to the results in the first interview, larger percentages now opted for the pre-school period as the optimal age. Pre-school learning of foreign languages (in kindergartens) is not a new phenomenon in Croatia and has been popular for quite some time now.

\section{Item14: Who speaks the foreign language you are learning?}

\section{Item 15: What are they like?}

The purpose of the items was to find out whether the young learners in the Project related the foreign language they were learning to its native speakers and to see what kind of idea they had of the native speakers.

The same criteria as in the first interview were used in grouping the answers: correctness of the answer, content reference and evaluation.

Item 14

\begin{tabular}{|l|c|c|c|}
\hline & English & French & German \\
\hline Correct & $81.6 \%$ & $95.5 \%$ & $95.4 \%$ \\
\hline Incorrect & $17.3 \%$ & $3.5 \%$ & $1.8 \%$ \\
\hline Don't know & $1.2 \%$ & $0 \%$ & $2.8 \%$ \\
\hline
\end{tabular}

The results show that the frequency of correct answers had significantly increased - obviously through the teaching/learning process the young learners became aware of 
the fact that the foreign language is connected to the native speakers and culture. The fact that in the English group the percentage of incorrect answers did not drop but even increased maybe reflects the present reality of the English language as a language for international communication: therefore it might be more difficult for the young learners to relate it to the native speaker groups. An interesting phenomenon can be observed in the German group: the number of "don't know" answers rose. One may possibly connect this with the fact that a lot of Croatian children have access to satellite TV and watch German channels where foreign programmes are dubbed so that even well-known American etc. characters (e.g., Alf) "speak” German.

Item 15

\begin{tabular}{|l|c|c|c|}
\hline & English & French & German \\
\hline Character & $45.3 \%$ & $51.8 \%$ & $66.7 \%$ \\
\hline Physical appearan. & $1.2 \%$ & $0 \%$ & $3.8 \%$ \\
\hline Cultural charact. & $3.5 \%$ & $18.8 \%$ & $5.7 \%$ \\
\hline Don't know & $22.1 \%$ & $9.4 \%$ & $12.4 \%$ \\
\hline Unclassifiable & $27.9 \%$ & $20.0 \%$ & $11.4 \%$ \\
\hline
\end{tabular}

\begin{tabular}{|l|c|c|c|}
\hline & English & French & German \\
\hline Positive & $62.5 \%$ & $65.9 \%$ & $68.7 \%$ \\
\hline Neutral & $36.1 \%$ & $31.8 \%$ & $30.3 \%$ \\
\hline Negative & $1.4 \%$ & $2.4 \%$ & $1.0 \%$ \\
\hline
\end{tabular}

The analysis of these results points to several interesting observations. In the German and English groups of learners a considerable drop in character descriptions can be noted, while the frequency of charaterizing the native speakers in terms of character remained the same in the French group. Except for the German group, the young learners seemed to have stopped thinkng of the native speakers in terms of their physical appearance too. As far as the cultural characteristics are concerned, a significant increase in the percentage in the French group can be noticed. It is only in the French group again that the drastic drop of "don't know" answers can be noticed too. What seems a little surprising is the appearance of considerable percentages of specific answers (termed 'Unclassifiable' in the table above) in all the three groups. One may suppose that, perhaps, the young learners had developed their own ideas and images of the native speakers that are rather idiosyncratic and dependent on child imagination.

As far as the evaluational aspect is concerned, the general observation is that very few beginners had negative attitudes towards the native speakers: in fact the major- 
ity (between 60 and 70 per cent) held positive views about them. The conspicuous changes refer to high increases in the positive evaluation in the English and French groups, while the rise in the German group was not significant. A drop in the neutral views can also be noted in the French and English groups. We may conclude that during the period of the two years since the first interview the young beginners developed further the positive attitudes about the native speakers that they started the foreign language learnig process with.

Our results differ from those in Lambert and Klineberg (1967) who, on the basis of a cross-national study of children's views of foreign peoples, conclude that the age of ten or so is the most beneficial for introducing cultural differences. They maintain that after this age as well as before it children tend to associate "different" with "bad". Our research shows that even at the age of 7 children are likely to view foreign people as different but at the same time interesting.

Item 16: Do your parents speak the foreign language you are learning?

Item 17: Do your parents speak any other foreign language?

Item 18: Do any of your relatives or friends speak the foreign language you are learning?

The learners' linguistic environment was questioned too. One may think of the environment as supportive if key figures in the child's life speak the foreign language he is learning in school.

Item 16

\begin{tabular}{|l|l|l|l|}
\hline & English & French & German \\
\hline Father only & $11.5 \%$ & $10.5 \%$ & $26.2 \%$ \\
\hline Mother only & $18.4 \%$ & $11.6 \%$ & $24.3 \%$ \\
\hline Both & $36.8 \%$ & $7.0 \%$ & $16.8 \%$ \\
\hline Neither & $33.3 \%$ & $70.9 \%$ & $32.7 \%$ \\
\hline
\end{tabular}

Item 17

\begin{tabular}{|l|l|c|l|}
\hline & English & French & German \\
\hline Father only & $16.1 \%$ & $14.0 \%$ & $24.3 \%$ \\
\hline Mother only & $14.9 \%$ & $9.3 \%$ & $21.5 \%$ \\
\hline Both & $36.8 \%$ & $73.3 \%$ & $43.9 \%$ \\
\hline Neither & $32.2 \%$ & $3.5 \%$ & $10.3 \%$ \\
\hline
\end{tabular}


Item 18

\begin{tabular}{|l|c|l|l|}
\hline & English & French & German \\
\hline None & $9.2 \%$ & $25.9 \%$ & $24.3 \%$ \\
\hline Relative & $12.6 \%$ & $30.6 \%$ & $25.2 \%$ \\
\hline Friend & $26.4 \%$ & $24.7 \%$ & $14.0 \%$ \\
\hline Both & $51.7 \%$ & $18.8 \%$ & $36.4 \%$ \\
\hline
\end{tabular}

These results show that our young learners, languagewise, lived in supportive environments. They also show that in their third year of learning a foreign language they were more aware of who speaks which foreign language in the family or among relatives and friends. In a way, a kind of consciousness-raising takes place in the young learner, who becomes aware that foreign languages exist in other people's lives as well.

Item 19: Did you know the foreign language before you started school?

Item 20: What did you know in this foreign language?

Item 21: Where did you learn it?

The possible pre-knowledge of the foreign language was looked into.

Item 19

\begin{tabular}{|l|l|l|l|}
\hline & English & French & German \\
\hline YES & $64.0 \%$ & $27.9 \%$ & $38.3 \%$ \\
\hline
\end{tabular}

The results differ a little from those of two years earlier. The young learners may have now got a different idea about what "knowing a language" means. The percentages realistically reflect the pre-school learning situation in the country.

Item 20

\begin{tabular}{|l|l|l|l|}
\hline & English & French & German \\
\hline Words & $85.7 \%$ & $90.6 \%$ & $84.6 \%$ \\
\hline Sentences & $14.3 \%$ & $9.4 \%$ & $15.4 \%$ \\
\hline
\end{tabular}

Except for the German group, most learners remember having known words in the foreign language before starting school in contrast to their statements two years earlier, when much higher percentages claimed they had known sentences as well. This may be connected with the developing cognitive maturity and language awareness. 
Item 21

\begin{tabular}{|l|c|c|c|}
\hline & English & French & German \\
\hline Kindergarten & $28.6 \%$ & $15.2 \%$ & $9.6 \%$ \\
\hline Parents & $12.5 \%$ & $21.2 \%$ & $36.5 \%$ \\
\hline Siblings & $14.3 \%$ & $9.1 \%$ & $3.8 \%$ \\
\hline FL course & $14.3 \%$ & $0 \%$ & $11.5 \%$ \\
\hline Grandparents & $1.8 \%$ & $3.0 \%$ & $15.4 \%$ \\
\hline Relatives, friends & $17.9 \%$ & $21.2 \%$ & $15.4 \%$ \\
\hline Other & $10.7 \%$ & $30.3 \%$ & $7.7 \%$ \\
\hline
\end{tabular}

These results also differ from the results of two years earlier. Again, one might say that the second interview revealed more realistic data. The results point to several trends in foreign language learning in Croatia. English is the foreign language that is most frequently learned in kindergartens, most grandparents and parents know German because that was the language that was most often taught in school at the time, among the siblings the most frequently learned foreign language is English.

\section{Item 22: What do your parents think about you learning this foreign language?}

This item aims at finding out about the learners' perception of the parents' attitude towards their learning of the foreign language.

Item 22

\begin{tabular}{|l|c|c|c|}
\hline & English & French & German \\
\hline Like it & $97.8 \%$ & $95.3 \%$ & $90.7 \%$ \\
\hline Don't care & $0 \%$ & $2.3 \%$ & $1.9 \%$ \\
\hline Don't like it & $0 \%$ & $1.2 \%$ & $0 \%$ \\
\hline Don't know & $1.2 \%$ & $1.2 \%$ & $7.5 \%$ \\
\hline
\end{tabular}

The results show that after almost three years of their children learning the foreign language in question more parents were happy with this fact. We may assume that the highly positive attitudes of the children as well as their enthusiasm influenced the parents' attitudes. This is in accordance with an earlier study of the change in parents' attitudes (Vilke, 1988). 


\section{Conclusion}

Our follow-up study of the young learners' attitudes and motivation for learning foreign languages has found several interesting things.

At the end of their third year of learning the young beginners of English, French and German as a foreign language still liked the foreign language they were learning and enjoyed their foreign language classes. Their initial positive attitudes to activities that had game elements now spread to most classroom events. At the age of 9, the young learners more often perceived what went on in class as learning and not only play, and they more often stated learning activities as their favourites. An overwhelming majority was still happy they were in the Project class and wanted to continue learning the foreign language. As far as their proficiency in the foreign language is concerned, the young learners were now more realistic and objective.

Being now more able to distinguish between general and personal benefits of knowing the foreign language in question, our young beginners saw increasing one's general knowledge as a benefit for all but they personally saw vocational rather than cultural value in such knowledge.

Having had some experience in learning a foreign language, the majority of young learners thought that age 7 was optimal but an increasing number of them opted for the pre-school period too.

Having been in touch with the new language for three years, a significantly larger number of learners knew who the native speakers are. The attitudes towards the native speakers became even more positive, which contrasts with the Lambert and Klineberg's (1967) finding that before the age of 10 children connect "different" with "bad".

According to their reports, the young learners lived in supportive environments languagewise. They were also more aware of who in their environment spoke foreign languages. They also looked more realistically at their past leanguage learning achievements.

As far as the parents are concerned more learners reported positive parental attitudes to their learning of the foreign language.

All these results lead to the conclusion that the affective variables of the young beginners show positive trends and desirable characteristics that may be viewed as conducive to successful foreign language learning. 


\section{Bibliography}

Carroll, J. (1969). Psychological and educational research into second language teaching to young children. In H.H. Stern (Ed.), Languages and the young child (pp. 56-68). London: Oxford University Press.

Curran, C. (1961). Counselling skills adapted to the learning of foreign languages. Bulletin of the Menninger Clinic 25, 78-93.

Low, L., Duffield, J., Brown, S. \& Johnstone, R. (1993). Evaluating foreign languages in primary schools. Stirling: Scottish CILT.

Lambert,W.E. \& Klineberg, O. (1967). Children's views of foreign peoples: A crossnational study. New York: Appleton.

Lennon, P. (1993). The advanced learner: affective, social and motivational factors. Language Learning Journal 8, 39-43.

Mihaljević Djigunović, J. (1993). Investigation of attitudes and motivation in early foreign language learning. In M. Vilke \& Y. Vrhovac (Eds.), Children and foreign languages (pp. 45-71). Zagreb: Faculty of Philosophy, University of Zagreb.

Schumann, J. (1978). The acculturation model for second language acquisition. In R. Gringras (Ed.), Second language acquisition and foreign language teaching (pp. 27-50). Arlington, VA: Center for Applied Linguistics.

Singleton, D.M. (1989). Language acquisition: the age factor. Clevedon, UK: Multilingual Matters.

Stengel, E. (1939). On learning a new language. International Journal of Psycho-Analysis 20, 471-79.

Vilke, M. (1976). The age factor in the acquisition of foreign languages. Rassegna Italiana di Linguistica Applicata 2/3, 179-190.

Vilke, M. (1979). English as a foreign language at the age of eight. SRAZ XXIV, 297-336.

Vogel, K. (1991). Lernen Kinder eine Fremdsprache anders als Erwachsene? Zur Frage des Einflusses des Alters auf den Zweitsprachenerwerb. Die Neueren Sprachen 5(90), 539-50. 